\title{
Detection of Usutu virus infection in wild birds in the United Kingdom, 2020
}

Arran J Folly ${ }^{1}$, Becki Lawson ${ }^{2}$, Fabian ZX Lean ${ }^{3}$, Fiona McCracken ${ }^{1}$, Simon Spiro ${ }^{4}$, Shinto K John² , Joseph P Heaver ${ }^{2}$, Katharina Seilern-Moy ${ }^{2}$, Nic Masters ${ }^{4}$, Luis M Hernández-Triana ${ }^{1}$, L Paul Phipps ${ }^{1}$, Alejandro Nuñez ${ }^{3}$, Anthony R Fooks ${ }^{1}$, Andrew A Cunningham ${ }^{2}$, Nicholas Johnson ${ }^{1}$, Lorraine M McElhinney ${ }^{1}$

1. Virology Department, Animal and Plant Health Agency, Surrey, United Kingdom

2. Institute of Zoology, Zoological Society of London, Regent's Park, London, United Kingdom

3. Pathology Department, Animal and Plant Health Agency, Surrey, United Kingdom

4. Wildlife Health Services, Zoological Society of London, Regent's Park, London, United Kingdom

Correspondence: Arran J. Folly (arran.folly@apha.gov.uk)

Folly Arran J, Lawson Becki, Lean Fabian ZX, McCracken Fiona, Spiro Simon, John Shinto K, Heaver Joseph P, Seilern-Moy Katharina, Masters Nic, HernándezTriana Luis M. Phipps L Paul, Nuñez Alejandro, Fooks Anthony R, Cunningham Andrew A, Johnson Nicholas, McElhinney Lorraine M. Detection of Usutu virus infection in wild birds in the United Kingdom, 2020. Euro Surveill. 2020;25(41):pii=2001732. https://doi.org/10.2807/1560-7917. ES.2020.25.41.2001732

In August 2020, as part of a long-term disease surveillance programme, Usutu virus was detected in five Eurasian blackbirds (Turdus merula) and one house sparrow (Passer domesticus) from Greater London, England. This was initially detected by reverse transcription-PCR and was confirmed by virus isolation and by immunohistochemical detection of flavivirus in tissues. Phylogenetic analysis identified Usutu virus African 3.2 lineage, which is prevalent in the Netherlands and Belgium, suggesting a potential incursion from mainland Europe.

In recent years, the zoonotic viruses, West Nile virus (WNV) and Usutu virus (USUV) have spread extensively throughout mainland Europe. Emergence is understood to be facilitated by the movement of wild birds, the vertebrate reservoir, and mosquitoes, the arthropod vector. This presents a risk of virus introduction to the United Kingdom (UK). As a result, dead wild birds in the UK are tested for both viruses during the vectoractive season.

During the late summer of 2020, USUV RNA was detected in six passerine birds found in Greater London. Here we confirm the details of the initial detection and molecular characterisation of the virus.

\section{Wild bird Flavivirus surveillance in the United Kingdom}

Usutu virus (family: Flaviviridae, genus: Flavivirus) is a single-stranded RNA virus that is maintained in a natural enzootic cycle between mosquitoes, which act as vectors, and birds, which are the main amplifying hosts [1]. Epizootics involving large-scale bird dieoffs have occurred across mainland Europe, including Belgium and the Netherlands [2,3], but with no evidence of emergence in the United Kingdom (UK). As part of a long-term disease surveillance programme in Great Britain (2005 until present), coordinated by the Institute of Zoology (https://www.gardenwildlifehealth.org) and the Animal and Plant Health Agency, morbidity and mortality in wild birds is recorded and carcasses are submitted for post-mortem examination (PME). Targeted surveillance for WNV and USUV is conducted on samples collected from these wild birds during the active mosquito season, April to November inclusive [4]. Since 2005 , samples from more than 2,550 wild birds have been submitted for molecular testing, of which 643 have been screened specifically for USUV.

\section{Outbreak identification and confirmation}

Between 15 July and 26 August 2020, five Eurasian blackbirds (Turdus merula) and one house sparrow (Passer domesticus) were submitted from a single area in Greater London. PMEs were conducted according to a standardised protocol [5]. The blackbirds comprised three adult males in thin or emaciated condition, based on assessment of muscle condition and body fat reserves, and two juveniles of undetermined sex in normal body condition. Clinical signs had been observed in two of the blackbirds: one was dehydrated and unable to grip, and was therefore euthanised on welfare grounds; the second was found unresponsive and subsequently died. The house sparrow was an adult male in thin body condition that was found dead.

Following PME, total RNA was extracted from brain and kidney samples to screen for USUV, WNV and Sindbis virus (SINV). Neither WNV nor SINV RNA was detected in any of the samples, however, USUV RNA was detected in all samples using a specific reverse transcription PCR (RT-PCR) assay [6] (cycle threshold (Ct) range: 21.94-30.90). Detection of USUV RNA was confirmed 


\section{FIGURE 1}

Detection of flavivirus envelope antigen in blackbird (Turdus merula) and house sparrow (Passer domesticus) using immunohistochemistry on formalin-fixed paraffinembedded tissue sections, United Kingdom, 2020

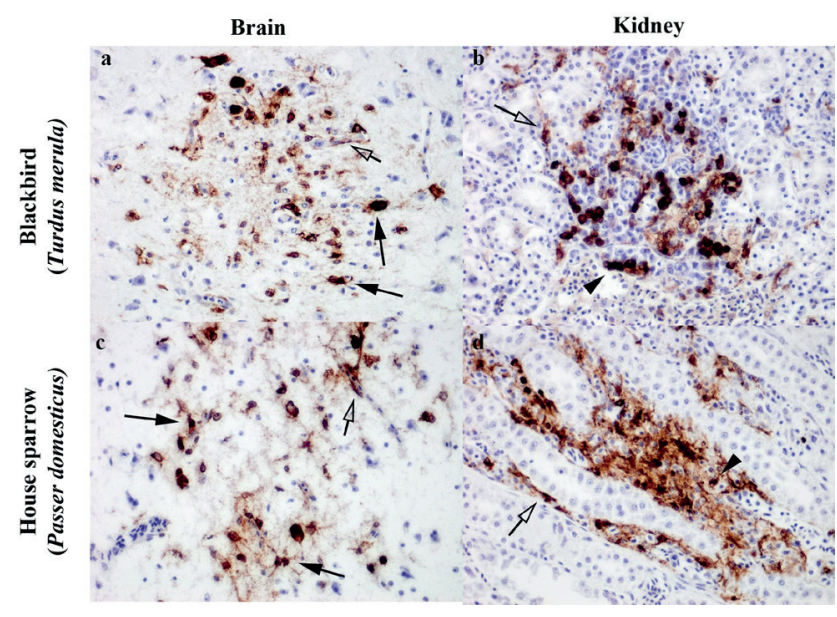

Solid arrow: neurons; non-solid arrow: endothelial cells; solid arrow head: renal tubular epithelial cells. Images taken at $400 \times$ magnification.

using a pan-flavivirus RT-PCR [7] that provided sufficient amplicon (165 bp) for Sanger sequencing. All sequences showed $100 \%$ similarity to USUV African 3.2 lineage (GenBank accession number: MN122254), isolated from a blackbird in the Netherlands [2]. We also sequenced the cytochrome oxidase 1 gene to confirm host species identity of tissue samples (Supplementary material). In addition, we have isolated USUV from RT-PCR-positive brain and kidney tissues from all six birds using Vero cells. This has been confirmed by visualisation of cytopathic effect and RT-PCR [6].

Flavivirus envelope (E) antigen was detected by immunohistochemistry on formalin-fixed paraffin-embedded tissue sections from all six birds. Tissue sections were quenched for endogenous peroxidase activity, virus antigens retrieved with proteinase enzyme buffer (DAKO, Glostrup, Denmark), followed by immunolabelling with mouse monoclonal antibody against flavivirus E antigen (ab155882, Abcam, Cambridge, UK; $2 \mu \mathrm{g} / \mathrm{mL}$ ) or a concentration-matched mouse IgG class $2 \mathrm{a}$ isotype control (ab18415, Abcam, Cambridge, UK). Tissue sections were then incubated with DAKO mouse EnVision + System and horseradish peroxidase (DAKO, Glostrup, Denmark), visualised using 3,3-diaminobenzidine (Sigma Aldrich, Missouri, United States (US)) and counterstained in Mayer's haematoxylin (Leica, Illinois, US). We used Vero cells infected with Japanese encephalitis virus or WNV as positive controls for flavivirus immunolabelling. Usutu RNA negative birds were used as negative controls (Supplementary material).

Brain and kidney samples were used to confirm presence of virus antigen to corroborate the RT-PCR results. Light microscopy examination of the brain and kidney sections of each of the blackbirds and house sparrow revealed positive immunolabelling for flavivirus $E$ antigens. In the brains of five birds (brain not available for histology from one blackbird), virus antigens were present in the neurons (Figure $1 \mathrm{a}$ and, c). In the kidneys of all six birds, presence of virus antigens in renal tubules were associated with mild to moderate multifocal lymphoplasmacytic tubulointerstitial nephritis (Figure $1 \mathrm{~b}$ and d). In addition, capillaries in the brain and kidney from both passerine species were immunopositive for flavivirus antigens (Figure 1).

\section{Sequence analysis}

Extracted RNA samples were submitted for next generation sequencing (NGS). A Nextera XT DNA library preparation kit ( $2 \times 150 \mathrm{bp}$ reads, Illumina, San Diego, US) was used for library preparation. Sequencing was carried out on an Illumina MiSeq sequencer. We performed a de novo assembly using SPAdes v3.14.1 on one blackbird sample (based on Ct value, see Supplementary material) and used the resulting contig list as a seed for a BLAST search. One contig (10,922 bp) aligned to an USUV African 3.2 isolate (GenBank accession number: MN122254; 99.80\% identity). We used the de novo contig to align reads from all six RNA extractions using a combination of Burrows-Wheeler Aligner v0.7.13 and SAMtools v1.9. Read alignment and genome coverage for all sequences was inspected in Tablet v1.19.09.03 (Supplementary material). Following consensus construction, the de novo assembled Greater London 2020 sequence (GenBank accession number: MWo01216) was aligned against 17 USUV GenBank sequences (Supplementary material) in Mafft v7.471. The alignment was imported into BEAST v1.10.4 and used to construct a Bayesian phylogenetic tree using the $G T R+I+G$ nucleotide substitution model and 10,000,000 Markov chain Monte Carlo generations (Figure 2). Log files were analysed in Tracer v1.7.1 to check effective sample size and a 10\% burn-in was included (TreeAnnotator v1.10.4), before tree visualisation and annotation in FigTree v1.4.4. The Greater London 2020 sequence formed a distinct, well supported clade with African 3.2 lineages of USUV. The NGS reads failed to align to a European WNV genome (GenBank accession number: $\mathrm{MH}$ 24836).

\section{Discussion}

Here we present data to support the emergence of USUV in wild birds in the UK in 2020. Our results show that an African 3.2 lineage of USUV has infected two species of wild birds in Greater London. Given that mortality occurred over a 5 -week period, it is likely that autochthonous transmission of USUV in local passerine populations has occurred, probably vectored by indigenous mosquitoes [1]. While there have been previous reports of USUV neutralising antibodies from birds in the UK, the authors did not report detecting virus using either virus isolation or molecular methods $[8,9]$. In addition, targeted wild bird disease surveillance for USUV since 2005 has not detected earlier virus incursions [4]. However, it is important to note that our detection is unlikely to represent the incursion 
Bayesian phylogenetic tree of a de novo assembled USUV lineage from an infected blackbird (Turdus merula), United Kingdom, 2020

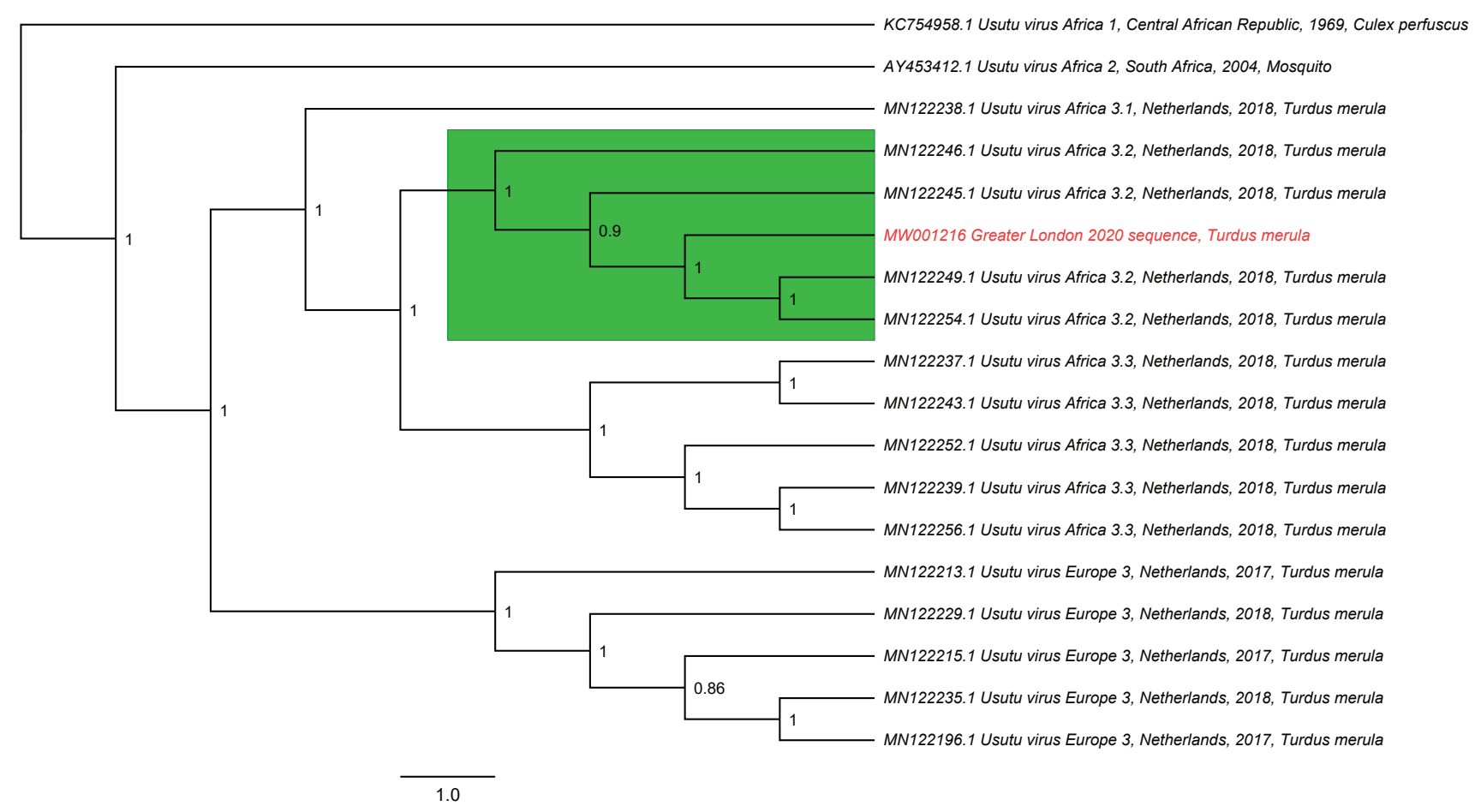

USUV: Usutu virus.

The tree is based on 10,922 bp of coding sequence from the USUV genome. The Greater London 2020 sequence (highlighted in red) forms a distinct clade with Africa 3.2 lineages previously detected in the Netherlands (highlighted in green). Node labels represent posterior probabilities and scale bar represents substitutions per site. Accession number, country, year of detection and host species are included for each sequence.

event, which may have occurred at an earlier date and at another location where emergence may have been facilitated by migratory birds or transported mosquitoes [2]. The average temperature in the late spring and early summer of 2020 in the UK was $1-2{ }^{\circ} \mathrm{C}$ higher than average [10], which may have been permissive for USUV replication and subsequent transmission by mosquito vectors, allowing its establishment in native wild bird populations. Mosquito surveillance, in collaboration with Public Health England, is being conducted in the location where the infected birds were found, to ascertain whether USUV is circulating in local vectors. On 30 September 2020, mosquitoes were active at the index site and therefore, if climatic conditions are permissible, transmission of USUV to wild birds may be ongoing.

The USUV Africa 3.2 lineage is widespread in mainland Europe and presents a likely source population for the identified UK outbreak [2]. Originally isolated in South Africa in 1959, USUV has since emerged across mainland Europe, following a similar pattern to the closely related WNV [11]. There are 10 recognised USUV lineages co-circulating in Europe, and this is likely to be a result of independent introduction events [12].
Consequently, other lineages of USUV may emerge in the UK.

Turdus merula and $P$. domesticus are susceptible to USUV and can develop systemic infections which our findings corroborate [13-17]. Indeed, infection with USUV has caused morbidity and mortality across Europe in passerines, especially T. merula, sometimes on a scale sufficient to cause population declines [18]. Although infection in humans is rare, USUV is a zoonosis that is predominantly asymptomatic but can result in neurological disease $[19,20]$. In addition, the virus can also be transmitted by blood transfusion, highlighting the importance for USUV screening of blood products as a preventative control measure [21,22]. In light of our findings, the UK government's Human Animal Infections and Risk Surveillance group (HAIRS) has revised and increased its public health risk assessment for USUV, to a low probability of transmission and a low to moderate impact [23]. In addition, the HAIRS report recommends that the Standing Advisory Committee on Transfusion Transmitted Infections, the Advisory Committee on Dangerous Pathogens, and the UK Zoonosis Network are to be advised of the revised public health risk within the UK [23]. The detection of USUV in the UK has implications for both animal and 
public health and future outbreaks in wild birds may occur and should be monitored.

\section{Acknowledgements}

The authors would like to thank members of the public who report and submit samples to the Garden Wildlife Health project, Ethan Wrigglesworth and Shaheed Macgregor for pathology support and the central sequencing unit (Animal and Plant Health Agency). The Garden Wildlife Health project is coordinated by the Institute of Zoology in collaboration with the British Trust for Ornithology, Froglife and the Royal Society for the Protection of Birds.

Funding: This research was funded in part by the Department for Environment, Food and Rural Affairs (DEFRA) and the Scottish and Welsh Governments through project SV3045. In addition, the Garden Wildlife Health project is financially supported by DEFRA and the Welsh Government through the Animal \& Plant Health Agency's Diseases of Wildlife Scheme Scanning Surveillance Programme (ProjectED1600), the Esmée Fairbairn Foundation, the Universities Federation for Animal Welfare and The Banister Charitable Trust. Virus characterisation work was funded by the European Union Horizon 2020-funded Research Infrastructure Grant 'European Virus Archive Global (EVAg)' under grant agreement number 871029 .

\section{Conflict of interest}

None declared.

\section{Authors' contributions}

Methodology: AJF, BL, FZXL, FMC, NJ, LMH-T, JPH, NM, LPP, SKJ, KSM, NM \& SS. Formal analysis: AJF, BL, SS, FZXL, LMH-T. Investigation: all authors. Resources: NJ, AN, ARF, LMM, AAC. Writing, review and editing: all authors. Funding acquisition and supervision: AAC, BL ARF, NJ, LMM.

\section{References}

1. Williams MC, Simpson DIH, Haddow AJ, Knight EM. The isolation of West Nile virus from a man and of Usutu virus from the bird-biting mosquito Mansonia aurites (Theobald) in the Entebbe area of Uganda. Ann Trop Med Parasitol. 1964;58(3):367-74. https://doi.org/10.1080/00034983.1964.11 686258 PMID: 14212897

2. Cadar D, Lühken R, van der Jeugd H, Garigliany M, Ziegler $U$, Keller $M$, et al. Widespread activity of multiple lineages of Usutu virus, western Europe, 2016. Euro Surveill. 2017;22(4):30452. https://doi.org/10.2807/1560-7917. ES.2017.22.4.30452 PMID: 28181903

3. Oude Munnink BB, Münger E, Nieuwenhuijse DF, Kohl R, van der Linden A, Schapendonk CME, et al. Genomic monitoring to understand the emergence and spread of Usutu virus in the Netherlands, 2016-2018. Sci Rep. 2020;10(1):2798. https:// doi.org/10.1038/s41598-020-59692-y PMID: 32071379

4. Horton DL, Lawson B, Egbetade A, Jeffries C, Johnson N, Cunningham AA, et al. Targeted surveillance for Usutu virus in British birds (2005-2011). Vet Rec. 2013;172(1):17. https://doi. org/10.1136/vr.101275 PMID: 23193038

5. Lawson B, Howard T, Kirkwood JK, Macgregor SK, Perkins $M$, Robinson RA, et al. Epidemiology of salmonellosis in garden birds in England and Wales, 1993 to 2003. EcoHealth. 2010;7(3):294-306. https://doi.org/10.1007/\$10393-010-03493 PMID: 20945078

6. Jöst H, Bialonski A, Maus D, Sambri V, Eiden M, Groschup MH, et al. Isolation of usutu virus in Germany. Am J Trop Med Hyg. 2011;85(3):551-3. https://doi.org/10.4269/ajtmh.2011.11-0248 PMID: 21896821

7. Johnson N, Wakeley PR, Mansfield KL, McCracken F, Haxton B, Phipps LP, et al. Assessment of a novel real-time pan-flavivirus
RT-polymerase chain reaction. Vector Borne Zoonotic Dis. 2010;10(7):665-71. https://doi.org/10.1089/vbz.2009.0210 PMID: 20854019

8. Buckley A, Dawson A, Moss SR, Hinsley SA, Bellamy PE, Gould EA. Serological evidence of West Nile virus, Usutu virus and Sindbis virus infection of birds in the UK. J Gen Virol. 2003;84(Pt 10):2807-17. https://doi.org/10.1099/vir.0.19341-0 PMID: 13679615

9. Buckley A, Dawson A, Gould EA. Detection of seroconversion to West Nile virus, Usutu virus and Sindbis virus in UK sentinel chickens. Virol J. 2006;3(1):71. https://doi.org/10.1186/1743422X-3-71 PMID: 16952307

10. Met Office. Climate summaries. Exeter: Met Office; [Accessed: 10 Sep 2020]. Available from: https://www.metoffice.gov.uk/ research/climate/maps-and-data/summaries/index

11. Vilibic-Cavlek T, Savic V, Petrovic T, Toplak I, Barbic L, Petric $D$, et al. Emerging trends in the epidemiology of West Nile and Usutu virus infections in Southern Europe. Front Vet Sci. 2019;6:437. https://doi.org/10.3389/fvets.2019.00437 PMID: 31867347

12. Engel D, Jöst H, Wink M, Börstler J, Bosch S, Garigliany MM, et al. Reconstruction of the evolutionary history and dispersal of Usutu virus, a neglected emerging arbovirus in Europe and Africa. MBio. 2016;7(1):e01938-15. https://doi.org/10.1128/ mBio.01938-15 PMID: 26838717

13. Steinmetz HW, Bakonyi T, Weissenböck H, Hatt JM, Eulenberger $\mathrm{U}$, Robert N, et al. Emergence and establishment of Usutu virus infection in wild and captive avian species in and around Zurich, Switzerland--genomic and pathologic comparison to other central European outbreaks. Vet Microbiol. 2011;148(24):207-12. https://doi.org/10.1016/j.vetmic.2010.09.018 PMID: 20980109

14. Benzarti E, Rivas J, Sarlet M, Franssen M, Desmecht D, Schmidt-Chanasit J, et al. Experimental Usutu virus infection in domestic canaries Serinus canaria. Viruses. 2020;12(2):164. https://doi.org/10.3390/v12020164 PMID: 32023880

15. Becker N, Jöst H, Ziegler U, Eiden M, Höper D, Emmerich P, et al. Epizootic emergence of Usutu virus in wild and captive birds in Germany. PLoS One. 2012;7(2):e32604. https://doi. org/10.1371/journal.pone.0032604 PMID: 22389712

16. Chvala S, Kolodziejek J, Nowotny N, Weissenböck H. Pathology and viral distribution in fatal Usutu virus infections of birds from the 2001 and 2002 outbreaks in Austria. J Comp Pathol. 2004;131(2-3):176-85. https://doi.org/10.1016/j. jcpa.2004.03.004 PMID: 15276857

17. Rijks JM, Kik ML, Slaterus R, Foppen R, Stroo A, IJzer J, et al. Widespread Usutu virus outbreak in birds in the Netherlands, 2016. Euro Surveill. 2016;21(45):30391. https://doi. org/10.2807/1560-7917.ES.2016.21.45.30391 PMID: 27918257

18. Lühken R, Jöst H, Cadar D, Thomas SM, Bosch S, Tannich E, et al. Distribution of Usutu virus in Germany and its effect on breeding bird populations. Emerg Infect Dis. 2017;23(12):19942001. https://doi.org/10.3201/eid2312.171257 PMID: 29148399

19. Pecorari M, Longo G, Gennari W, Grottola A, Sabbatini A, Tagliazucchi S, et al. First human case of Usutu virus neuroinvasive infection, Italy, August-September 2009. Euro Surveill. 2009;14(50):19446. PMID: 20070936

20. Nagy A, Mezei E, Nagy O, Bakonyi T, Csonka N, Kaposi M, et al. Extraordinary increase in West Nile virus cases and first confirmed human Usutu virus infection in Hungary, 2018. Euro Surveill. 2019;24(28):1900038. https://doi.org/10.2807/15607917.ES.2019.24.28.1900038 PMID: 31311619

21. Carletti F, Colavita F, Rovida F, Percivalle E, Baldanti F, Ricci I, et al. Expanding Usutu virus circulation in Italy: detection in the Lazio region, central Italy, 2017 to 2018. Euro Surveill. 2019;24(3):1800649. https://doi.org/10.2807/1560-7917. ES.2019.24.3.1800649 PMID: 30670139

22. Zaaijer HL, Slot E, Molier M, Reusken CBEM, Koppelman MHGM. Usutu virus infection in Dutch blood donors. Transfusion. 2019;59(9):2931-7. https://doi.org/10.1111/ trf.15444 PMID: 31270821

23. Human Animal Infections and Risk Surveillance Group. Qualitative assessment of the risk that Usutu virus presents to the UK population. London: Public Health England; 2020. Available from: www.gov.uk/government/publications/ hairs-risk-assessment-usutu-virus

\section{License, supplementary material and copyright}

This is an open-access article distributed under the terms of the Creative Commons Attribution (CC BY 4.0) Licence. You may share and adapt the material, but must give appropriate 
credit to the source, provide a link to the licence and indicate if changes were made.

Any supplementary material referenced in the article can be found in the online version.

This article is copyright of the authors or their affiliated institutions, 2020. 